\title{
GLP-1 Obesity and Diabetes Gerald H Tomkin and Daphne Owens
}

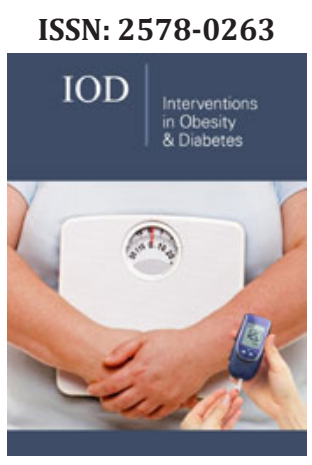

*Corresponding author: Gerald H Tomkin, Coillancoraig Lodge, Rocky valley Drive, Kilmacanogue, Ireland

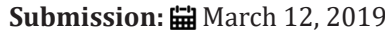

Published: 非 June 20, 2019

Volume 3 - Issue 1

How to cite this article: Gerald HT. GLP1 Obesity and Diabetes Gerald H Tomkin and Daphne Owens. Interventions Obes Diabetes. 3(1). IOD.000553.2019. DOI: 10.31031/IOD.2019.03.000553

Copyright@ Gerald HT, This article is distributed under the terms of the Creative Commons Attribution 4.0 International License, which permits unrestricted use and redistribution provided that the original author and source are credited.

\section{Gerald HT*}

Coillancarraig Lodge, Rocky Valley Drive, Kilmacanogue, Co Wicklow, Ireland

\begin{abstract}
Obesity is commonly associated with type 2 diabetes. Weight reduction in obese subjects is effective in both preventing the onset of type 2 diabetes and in reversing the condition once present. GLP1 agonists have been shown to inhibit appetite both by delaying gastric emptying and increasing saiety at a central level. These drugs have been shown to delay the onset of type 2 diabetes, to reverse diabetes and to lower blood sugar in patients with Type 2 diabetes. Development of these drugs has resulted in prolongation of absorption so that they may be given by subcutaneous injections and more recently reports of an oral preparation of semaglutide that has similar efficacy to the subcutaneous preparation have appeared. The drugs have been shown to result in cardiovascular protection.
\end{abstract}

Keywords: Diabetes; Extendin 1,2,3,4; GLP-1 Receptor; DPP-4; Oral Semaglutide; Obesity

Keywords: VIP: Vasoactive Intestinal Peptide

\section{Introduction}

Medical School did not teach us about lizards or if they did we failed to take notice. Now everyone is familiar with two venomous lizards, Heloderma suspectum (Gila monster) and close relative Heloderma horridium (Mexican bearded lizard). They live in the south of North America. The Gila monster is large, by lizard standards, being up to $700 \mathrm{~g}$ and $22 \mathrm{~cm}$ length. The venom is not fatal to adults but does cause severe pain, swelling, hypotension and lymphadenopathy. The venom contains more than a dozen peptides including serotonin and various vasoactive intestinal peptide (VIP)-like proteins (Exendins 1.2 and 3) which bind to VIP receptors. Exendin 3 binds to a VIP receptor to stimulate amylase release [1,2]. In 1992 Eng et al. [3] predicted a receptor for Exendin 4. They wrote "The presence of the exendin receptor, although functionally undefined at the present time, predicts the existence of an endogenous mammalian analog to the exendin peptides". Cloning and functional expression of the human islet GLP-1 receptor was described in 1993 Thorens et al. [4]. In 1999 Xu et al. [5] showed that exendin-4 improved glucose tolerance in diabetic rats and increased betacell mass through both beta cell replication and neogenesis. Exendin 4 is a GLP-1 like protein with a 50\% homology but with a much longer biological half-life. Szayna et al. [6] showed that exendin- 4 reacts with the GLP-1 receptor to induce insulin release. Exendin - 4 was found to be much more potent than GLP-1 with a much longer biological half-life. In Zucker fatty rats Exendin 4 was found to lower blood sugars but also to reduce food intake and reduce fat deposition. Edwards et al. [7] showed that GLP-1 reduced blood sugar and decreased energy intake in humans but the very short half-life due to rapid cleavage by the enzyme DPP-4 meant that the drug had to be given by intravenous infusion. Exendin - 4 does not have this problem as the molecule is not disrupted by DPP-4 therefore the biological half-life is much longer, it was known that incretins are glucose dependent with regards to their insulin stimulation effect. Egan et al. [8] demonstrated that exendin 4 is a potent and long lasting insulinotropic agent in both non-diabetic and diabetic subjects using a glucose clamp method. In 2003 Exendin-4 given in bolus subcutaneous doses was shown to reduce blood sugars and HbA1c [9]. Exendin 4 was shown to delay gastric emptying and reduce post prandial blood sugars in Type 1 diabetic patients [10].

A 30 week study of exenatide resulted in a modest weight loss of $1.6 \mathrm{~kg}$ and an improvement in $\mathrm{HbA} 1 \mathrm{c}$ of $0.86 \%$ [11]. Exenatide was launched on the market in 2006 and was followed by other GLP agonists that had been adapted in various ways to resist degradation 
by DPP-4. More recently GLP1 agonists and Exenatide have been further adapted to increase their biological half-life and now are given by subcutaneous injection only once a week. Semaglutide has been adapted to resist gastric degradation by co formulation with an absorption enhancer sodium N-[8(2-hydroxylbenzoyl) amino] caprylate (SNAC). The drug is unusual for a small molecule in being absorbed in the stomach. This protects against enzymatic degradation via local buffering actions and may have implication for other therapeutic peptides that might be transformed from injectable to oral preparations [12]. In a trial over a 26 week period the 2 highest doses or the oral agent was as effective in weight reduction as weekly subcutaneous semaglutide with a similar drop in $\mathrm{HbA} 1 \mathrm{c}$ of $1.6 \%$ for the highest oral dose used. compared to the subcutaneous weekly injection. Gastro intestinal side effects were common especially with the higher doses but with slow escalation of dose similar rates of discontinuation occurred as compared to the subcutaneous route [13].

Liraglutide is another GLP-1 agonist. It is a derivative of GLP1 obtained by acylation of the GLP-1 molecule [14]. The molecule is slowly released from the injection site and extensively bound to albumen which protects from degradation by DPP-4 while at the same time reducing renal clearance [15]. In one of the first studies in human type 2 diabetes Juhl et al. [16] showed that once daily injection of this compound was effective in lowering glucose and delaying gastric emptying. In a 26 week study in Type 2 Diabetes, Liraglutide at the highest dose $(1.8 \mathrm{mg})$ reduced $\mathrm{HbA} 1 \mathrm{c}$ by $1.0 \%$ and weight by $2.8 \mathrm{~kg}$ [17]. A more impressive reduction compared to exenatide as referenced above. In a comparison study of Liraglutide with exenatide over 26 weeks, liraglutide reduced HbA1c more than exenatide but post prandial glucose was less effectively controlled. Similar weight loss was recorded $(-3.24 \mathrm{~kg}$ viz $-2.87 \mathrm{~kg})[18,19]$. Another 26 week study comparing liraglutide to semaglutide showed semaglutide to have superior glucose lowering but with higher frequency of gastrointestinal adverse events.

A 3mg dose of liraglutide has been used in non-diabetic obese subjects to promote weight loss [20]. The subjects were obese with BMI of $30 \mathrm{~kg} / \mathrm{m}^{2}$ or more and had pre-diabetes, or $27 \mathrm{~kg} / \mathrm{m}^{2}$ if they had co morbidities. Fifty\% of subjects completed 160 weeks, $47 \%$ of the liraglutide subjects dropping out. Liraglutide subjects lost $4 \mathrm{~kg}$ more than the controls, a very modest weight loss for subjects who were about $95 \mathrm{~kg}$ at the start of the study. However, even this very modest weight reduction was associated with a prolongation of the time to development of diabetes. In a head to head study with semaglutide in obese subjects (BMI $30 \mathrm{Kg} / \mathrm{m}^{2}$ or more) for 52 weeks the subjects on semaglutide lost $13.8 \%$ body weight at the highest dose of $0.4 \mathrm{mg} /$ day as compared to $7.8 \%$ for Liraglutide and $2.3 \%$ for the placebo arm [21]. Eighty one percent of subjects completed the study. This study suggests that semaglutide has a considerable advantage over liraglutide in non-diabetic obese subjects, with a similar adverse and dropout rate. The study, of course, needs to be replicated for confirmation. The study suggests that longer follow up would result in even further weight loss.

Semaglutide is now available in a once a week formulation. In a 12 week study the weekly injection was shown to reduce fasting, post prandial and overall glucose and glucagon response. The drug increased insulin secretion rate [22]. Once a week semaglutide was compared to exenatide extended release in a 56 week trial [23]. Semaglutide, $1 \mathrm{mg}$ weekly, reduced $\mathrm{HbA} 1 \mathrm{c}$ by $1.5 \%$ as compared to $0.9 \%$ with exenatide ER $2 \mathrm{mg}$ weekly. Body weight reduced by $5.6 \mathrm{~kg}$ with semaglutide as compared to $1.9 \mathrm{~kg}$ with Exenatide ER. There were more gastrointestinal adverse events with semaglutide (41.8\% viz 33.3\%). It is not known whether this formulation over more than 56 weeks will cause further weight reduction. In a 56 week trial in comparison to sitagliptin, a DPP-4 inhibitor, semaglutide, $1 \mathrm{mg}$ weekly, reduced $\mathrm{HbA} 1 \mathrm{c}$ by $1.6 \%$ and weight by $6.1 \mathrm{~kg}$ from a starting weight of $89.5 \mathrm{~kg}$ (SD 20.3) [24]. Cardiovascular safety of oral semaglutide in patients with Type 2 diabetes is now being evaluated in the PIONEER 6 trial [25]. Gastrointestinal side effects are common in all GLP - 1 treatments due to delayed gastric emptying. Up to $27.2 \%$ of subjects experienced nausea or vomiting in the SUSTAIN 1 to 5 trials [26]. The Authors of this study suggested that the contribution of nausea or vomiting to the weight loss was minor. In real-life settings efficacy and adherence of GLP-1 receptor agonists for treatment of type 2 diabetes may not be satisfactory. A review recently [27] ended by suggesting that regular re-evaluations of treatment including response, tolerability, adherence, cost and quality of life, are necessary.

Diabetic patients are at high risk for cardiovascular events and there have been instances when drugs that should be theoretically cardioprotective have turned out to increase the risk of cardiovascular events. Thus, there is a lot of interest in studying the cardiovascular outcomes in any new diabetic medications. It seems that GLP1 agonists have some degree of cardiovascular protection. A meta analysis of cardiovascular outcomes with glucagon-like peptide- 1 receptor agonists in patients with type 2 diabetes found evidence of cardiovascular safety across all GLP-1 receptor agonist cardiovascular outcome trials and reduction in adverse cardiovascular events (Cardiovascular mortality, nonfatal myocardial infarction and non-fatal stroke) [28]. In a review of cardiovascular outcome trials of glucose-lowering medications Home [29] suggested that GLP-1 receptor agonists should be offered to all type 2 diabetic patients with cardiovascular disease. The mechanisms involved have been recently explored by Rakipovski et al. [30]. They found in apolipoprotein E-deficient mice that liraglutide and semaglutide modified plaque atherosclerotic progression. Further studies treating the mice with semaglutide revealed reversal of many of the genes involved in inflammation and plaque formation affected by a Western type atherosclerosis diet. The pathways included leucocyte recruitment, leucocyte rolling, adhesion/extravasation, cholesterol metabolism, lipid mediated signaling, extracellular matrix protein turnover and plaque haemorrhage. Cardiovascular benefit from GLP-1 agonists may not be the same for all ethnic groups. Kang et al. [31] found that in a meta analysis of cardiovascular outcome trials Asian populations may do better.

Rapid reduction of blood sugars in patients with poorly controlled diabetes may provoke retinopathy with exudate 
formation and a reduction of visual acuity. However, these changes are transitory and do not cause permanent damage. A 104 week study of semaglutide once a week at either a dose of $0.5 \mathrm{mg}$ or $1 \mathrm{mg}$ has now being evaluated in the SUSTAIN-6 study [32]. Eighty three percent of the patients had pre-existing retinopathy at base line. Rates of retinopathy complications were increased in the semaglutide patients ( $3 \%$ viz $1.8 \%$ in the placebo group) Rates of new or worsening nephropathy were lower in the semaglutide group. It is difficult to understand why semaglutide might worsen retinopathy but further studies are necessary as the numbers in this study too few to make firm conclusions. Vilsboll et al. [33] evaluated diabetic retinopathy data from across the SUSTAIN clinical trial program. They concluded that the worsening diabetic retinopathy in SUSTAIN 6 which was not found in SUSTAIN 1 to 5 may have been due to the rapidity and magnitude of improvement in glycaemic control. However, the reduction in HbA1c in the $1 \mathrm{mg}$ semaglutide group was only $1 \%$ more than the placebo group and there was no significant difference in hypoglycaemia episodes between the semaglutide and the placebo groups.

\section{Conclusion}

Two venemous lizards have come to the aid of type 2 diabetic patients. GLP-1 agonists are useful in both lowering blood sugar and in cardiovascular and renal protection. A recent trial of once weekly semaglutide suggests that this drug may be the most effective in weight reduction and it is exciting that an oral preparation with similar efficacy to the subcutaneous injectable form may come to the market soon. The gastrointestinal side effects causing the high dropout rate in clinical trials necessitates considerable discussion and persuasion with many patients. Although the drugs have few other side effects, there is a concern in just one trial about the progression of retinopathy. This concern will be assessed in further trials. The prevention of onset of diabetes in type 2 subjects, suggests a wider use of this class of drugs.

\section{References}

1. Wikipedia, the free encyclopedia.

2. Irwin DM (2012) Origin and convergent evolution of exendin genes. Gen Comp Endocrinol 175(1): 27-33.

3. Eng J, Berson S (1992) Exendin peptides. Mt Sinai J Med 59(2): 147-149.

4. Thorens B, Porret A, Bühler L, Deng SP, Morel P, et al. (1993) Cloning and functional expression of the human islet GLP-1 receptor. Diabetes 42(11): 1678-1682.

5. Xu G, Stoffers DA, Habener JF, Bonner WS (1999) Exendin-4 stimulates both beta-cell replication and neogenesis, resulting in increased betacell mass and improved glucose tolerance in diabetic rats. Diabetes 48(12): 2270-2276.

6. Szayna M, Doyle ME, Betkey JA, Holloway HW, Spencer RG, et al. (2000) Exendin-4 decelerates food intake, weight gain, and fat deposition in Zucker rats. Endocrinology 141(6): 1936-1941.

7. Edwards C, Stanley S, Davis R, Brynes A, Frost G (2001) Exendin-4 reduces fasting and postprandial glucose and decreases energy intake in healthy volunteers. Am J Physiol Endocrinol Metab 281(1): E155-E161.

8. Egan JM, Clocquet AR, Elahi D (2002) The insulinotropic effect of acute exendin-4 administered to humans: Comparison of nondiabetic state to type 2 diabetes. J Clin Endocrinol Metab 87(3): 1282-1290.
9. Egan JM, Meneilly GS, Elahi D (2003) Effects of 1-mo bolus subcutaneous administration of exendin-4 in type 2 diabetes. Am J Physiol Endocrinol Metab 284(6): E1072-1079.

10. Dupré J, Behme MT, McDonald TJ (2004) Exendin-4 normalized postcibal glycemic excursions in type 1 diabetes. J Clin Endocrinol Metab 89(7): 3469-3473.

11. Buse JB, Henry RR, Han J, Kim DD, Fineman MS, et al. (2004) Effects of exenatide (exendin-4) on glyemic control over 30 weeks in sulfonylureatreated patients with type 2 diabetes. Diabetes Care 27(11): 2628-2635.

12. Buckley ST, Bækdal TA, Vegge A, Maarbjerg SJ, Pyke C, et al. (2018) Transcellular stomach absorption of a derivatized glucagon-like peptide-1 receptor agonist. Sci Transl Med 10(467) pii: eaar7047.

13. Davies M, Pieber TR, Hartoft NM, Hansen OKH, Jabbour S, et al. (2017) Effect of oral semaglutide compared with placebo and subcutaneous semaglutide on glycemic control in patients with type 2 diabetes: A randomized clinical trial. JAMA 318(15): 1460-1470.

14. Knudsen LB, Nielsen PF, Huusfeldt PO, Johansen NL, Madsen K, et al. (2000) Potent derivatives of glucagon-like peptide-1 with pharmacokinetic properties suitable for once daily administration. J Med Chem 43(9): 1664-1669.

15. Rolin B, Larsen MO, Gotfredsen CF, Deacon CF, Carr RD, et al. (2002) The long-acting GLP-1 derivative NN2211 ameliorates glycemia and increases beta-cell mass in diabetic mice. Am J Physiol Endocrinol Metab 283(4): E745-E752.

16. Juhl CB, Hollingdal M, Sturis J, Jakobsen G, Agersø H, et al. (2002) Bedtime administration of NN2211, a long-acting GLP-1 derivative, substantially reduces fasting and postprandial glycemia in type 2 diabetes. Diabetes 51(2): 424-429.

17. Nauck M, Frid A, Hermansen K, Shah NS, Tankova T, et al. (2009) Efficacy and safety comparison of liraglutide, glimepiride, and placebo, all in combination with metformin, in type 2 diabetes: the LEAD (liraglutide effect and action in diabetes)-2 study. Diabetes Care 32(1): 84-90.

18. Buse JB, Rosenstock J, Sesti G, Schmidt WE, Montanya E, et al. (2009) LEAD-6 Study Group. Liraglutide once a day versus exenatide twice a day for type 2 diabetes: A 26-week randomised, parallel-group, multinational, open-label trial (LEAD- 6). Lancet 374(9683): 39-47.

19. Lingvay I, Desouza CV, Lalic KS, Rose L, Hansen T, et al. (2018) A 26-Week randomized controlled trial of semaglutide once daily versus liraglutide and placebo in patients with type 2 diabetes suboptimally controlled on diet and exercise with or without metformin. Diabetes Care 41(9): 19261937.

20. le Roux CW, Astrup A, Fujioka K, Greenway F, Lau DCW, et al. (2017) 3 years of liraglutide versus placebo for type 2 diabetes risk reduction and weight management in individuals with prediabetes: A randomised, double-blind trial. Lancet 389(10077): 1399-1409.

21. O Neil PM, Birkenfeld AL, McGowan B, Mosenzon O, Pedersen SD, et al. (2018) Efficacy and safety of semaglutide compared with liraglutide and placebo for weight loss in patients with obesity: A randomised, doubleblind, placebo and active controlled, dose-ranging, phase 2 trial. Lancet 392(10148): 637-649.

22. Kapitza C, Dahl K, Jacobsen JB, Axelsen MB, Flint A (2017) Effects of semaglutide on beta cell function and glycaemic control in participants with type 2 diabetes: A randomised, double-blind, placebo-controlled trial. Diabetologia 60(8): 1390-1399.

23. Ahmann AJ, Capehorn M, Charpentier G, Dotta F, Henkel E, et al. (2018) Efficacy and safety of once-weekly semaglutide versus exenatide er in subjects with type 2 diabetes (SUSTAIN 3): A 56-week, open-label, randomized clinical trial. Diabetes Care 41(2): 258-266.

24. Ahrén B, Masmiquel L, Kumar H, Sargin M, Karsbøl JD, et al. (2017) Efficacy and safety of once-weekly semaglutide versus once-daily sitagliptin as an add-on to metformin, thiazolidinediones, or both, in patients with type 2 diabetes (SUSTAIN 2): A 56-week, double-blind, 
phase 3a, randomised trial. Lancet Diabetes Endocrinol 5(5): 341-354.

25. Bain SC, Mosenzon O, Arechavaleta R, Bogdański P, Comlekci A, et al. (2019) Cardiovascular safety of oral semaglutide in patients with type 2 diabetes: Rationale, design and patient baseline characteristics for the PIONEER 6 trial. Diabetes Obes Metab 21(3): 499-508.

26. Ahrén B, Atkin SL, Charpentier G, Warren ML, Wilding JPH, et al. (2018) Semaglutide induces weight loss in subjects with type 2 diabetes regardless of baseline BMI or gastrointestinal adverse events in the SUSTAIN 1 to 5 trials. Diabetes Obes Metab 20(9): 2210-2219.

27. Guerci B, Charbonnel B, Gourdy P, Hadjadj S, Hanaire H, et al. (2019) Efficacy and adherence of glucagon-like peptide-1 receptor agonist treatment in patients with type 2 diabetes mellitus in real-life settings. Diabetes Metab pii: S1262-3636(19): 30021-30027.

28. Bethel MA, Patel RA, Merrill P, Lokhnygina Y, Buse JB, et al. (2018) Cardiovascular outcomes with glucagon-like peptide-1 receptor agonists in patients with type 2 diabetes: A meta-analysis. Lancet Diabetes Endocrinol 6(2): 105-113.
29. Home P (2019) Cardiovascular outcome trials of glucose-lowering medications: An update. Diabetologia 62(3): 357-369.

30. Rakipovski G, Rolin B, Nøhr J, Klewe I, Frederiksen KS, et al. (2018) The GLP-1 analogs liraglutide and semaglutide reduce atherosclerosis in apoe-/- and ldlr-/-mice by a mechanism that includes inflammatory pathways. JACC Basic Transl Sci 3(6): 844-857.

31. Kang YM, Cho YK, Lee J, Lee SE, Lee WJ, et al. (2018) Asian subpopulations may exhibit greater cardiovascular benefit from long-acting glucagonlike peptide 1 receptor agonists: A meta-analysis of cardiovascular outcome trials. Diabetes Metab.

32. Marso SP, Bain SC, Consoli A, Eliaschewitz FG, Jódar E, et al. (2016) Semaglutide and cardiovascular outcomes in patients with type 2 diabetes. N Engl J Med 375(19): 1834-1844.

33. Vilsbøll T, Bain SC, Leiter LA, Lingvay I, Matthews D, et al. (2018) Semaglutide, reduction in glycated haemoglobin and the risk of diabetic retinopathy. Diabetes Obes Metab 20(4): 889-897. 